\title{
Synthesis and Characterization of Styrenated Poly(ester-amide) Resin from Melia Azedarach Seed Oil -An Eco-friendly Resource
}

\author{
SAGEER AHAMAD, S. A. AHMAD and A. HASNAT*
}

Natural Product and Polymer Research Laboratory, Department of Chemistry, G.F. College (M.J.P. Rohilkhand University) Shahjahanpur, U.P. 242001, India

hasnatgfc@rediffmail.com

Received 26 July 2015 / Accepted 12 August 2015

\begin{abstract}
Due to fast depletion of petrochemical stock and environmental concern both, utilization of vegetable oils as a renewable resource in the synthesis of polymeric materials are in the spotlight of the chemical industries. Keeping these facts in mind we have attempted to utilize Melia azedarach seed oil (MASO), a renewable and eco-friendly resource presently rot away at the various plantations in each season in the synthesis of styrenated poly(ester-amide) resin (SMAPEA). The poly (ester-amide) (MAPEA) was prepared by the aminolysis of triglyceride oil with diethanol amine followed by the poly (condensation) with phthalic acid. The MAPEA then treated with styrene in different per hundred of resin (phr) to obtain a series of SMAPEA resins. The synthesized intermediates and final resins have been characterized by the measuring the physico-chemical properties as per standard laboratory methods and spectral analyses. The coatings of SMAPEA were also tested for physico-mechanical performances.
\end{abstract}

Keywords: Vegetable oil, Styrene, Poly(ester-amide), Renewable resource, Melia azedarach

\section{Introduction}

Vegetable oil based poly(ester-amide) are amide modified alkyds that have improved film properties over normal alkyds in terms of drying time, hardness, water vapor resistance, chemical and thermal resistance ${ }^{1-3}$. In addition to these poly(ester-amide) resins are also known for high durability in many service environment ${ }^{4,5}$. However, their use as a versatile coating material is restricted due to their high baking temperature for curing ${ }^{5,6}$. Incorporation of metals, metalloids and organic moieties like styrene, vinyl acetate, acrylates reduce the curing temperature of the resin appreciably ${ }^{1,7}$. Modification of the oil based polymeric resins with the styrene monomer or its copolymer with other acrylic monomers not only reduces the baking temperature but also enhances the scratch hardness, protective efficiency and thermal stability ${ }^{7,8}$. 
Developments of polymeric resins from renewable resources have attracted a lot of attention of the academia and scientist throughout the world ${ }^{9-11}$. This is due to depletion of world petrochemical stock and environmental concern both ${ }^{12}$. Utilization of vegetable oils for the synthesis of polymeric materials are in the spotlight of the chemical industries as they are largest renewable resource due to their abundant availability, built in biodegradability, low eco-toxicity as well low-toxicity towards humans and annual renewability ${ }^{13-15}$. Common seed oils such as linseed ${ }^{16}$, castor $^{17}$, soybean ${ }^{18}$ and sunflower ${ }^{19}$ have been largely used in the synthesis of low molecular weight polymers like alkyds, epoxies, poly(urethane)s, poly(ester-amide)s and many others ${ }^{1,2,20}$. These polymers are extensively used in the coatings, paints and adhesives industries. The meager utilization of non-edible seed oils has prompted the scientist to develop ways to utilize such seed oils.

Melia azedarach is a moderate size tree and widely grown in India. Its seed contain about $40 \%$ oil, which posses' large amount of unsaturated fatty acids ${ }^{21}$. Literature survey reveals that Melia azedarach seed oil is abundantly available in the country and still not being utilized satisfactorily especially in the synthesis of polymeric materials ${ }^{16-20}$. In present research work we have make an effort to synthesize the styrenated poly(ester-amide) resin from Melia azedarach seed oil (MASO) to take the advantage of both utilization of renewable resource with improved physicochemical properties due to styrene. The synthesized resins were characterized by physicochemical analysis and by spectral studies. The physico-mechanical performances of the polymeric films were also investigated.

\section{Experimental}

The seeds of Melia azedarach were collected from the different places of the shahjahanpur district,U.P., India. The oil was extracted by soxhlet apparatus from the dried and crushed seeds. Petroleum ether was used as a solvent $\left(60-80{ }^{\circ} \mathrm{C}\right)$. The results of physico-chemical characterizations and fatty acid composition of oil is given in the Table 1 . Phthalic acid, diethyl ether, styrene, methanol were used of analytical grade (Merck-India). Diethanol amine of analytical grade procured from the s.d. Fine Chemicals India and was distilled under reduced pressure before use.

Table 1. Characterization of MASO and HEMAFA

\begin{tabular}{cccc}
\hline S. No. & Characterization & MASO & HEMAFA \\
\hline 1. & Oil content & 40 & - \\
2. & Gardener color & 6 & 6 \\
3. & Specific gravity & 0.930 & 0.938 \\
4. & Refractive index & 1.4691 & 1.4697 \\
5. & Iodine value & 134.7 & 65.8 \\
6. & Acid Value & 4.45 & - \\
7. & Saponification value & 190.8 & - \\
8. & Fatty acid composition & & \\
& Saturated (Palmitic and stearic) & 11.4 & \\
\multicolumn{4}{c}{ Unsaturated (Oleic and Linoleic) } \\
\hline
\end{tabular}

\section{Syntheses}

Synthesis of N,N-bis (2-hydroxy ethyl) Melia azedarach oil fatty amide (HEMAFA)

HEMAFA was synthesis as per our earlier reported method for aminolysis of vegetable oil ${ }^{14}$. Diethanol amine $(0.32 \mathrm{~mol})$ and sodium methoxide $(0.007)$ was taken in four necked round bottom flask fitted with an electrical stirrer, thermometer, dropping funnel and condenser. 
The reaction mixture was heated at $180 \pm 5{ }^{\circ} \mathrm{C}$. The Melia azedarach oil $(0.1 \mathrm{~mol})$ was added drop wise into the reaction mixture over a period of $60 \mathrm{~min}$. The progress of the reaction was monitored by TLC (silica gel, GF-254 was used as a bonded phase and ethyl acetate as a mobile phase). After the completion of the reaction, the product was dissolve in diethyl ether and washed with dilute aqueous sodium chloride solution. The ethereal solution was filtered and evaporated in rotary vacuum evaporator to obtained HEMAFA.

\section{Synthesis of Melia azedarach Poly(ester-amide) (MAPEA)}

MAPEA have been synthesized by using a poly (condensation) polymerization between a diol and dibasic acid ${ }^{20}$. The equimolar amount of HEMAFA and Phthalic acid along with xylene as a solvent were taken in a four necked round bottom flask equipped with DeanStark trap, thermometer and mechanical stirrer. The reaction mixture was heated up to $200{ }^{\circ} \mathrm{C}$ under continuous stirring. The progress of reaction was monitored by taking acid values at regular intervals ${ }^{5}$. At the end of reaction, the product was cooled at room temperature. Excess of solvent was removed in a rotary vacuum evaporator under reduced pressure to obtain MAPEA.

\section{Styrene modified Poly(ester-amide) (SMAPEA)}

Poly(ester-amide) of Melia azedarach seed oil (MAPEA) dissolved in xylene placed in four necked round bottom flask equipped with water condenser, nitrogen inlet tube, thermometer and mechanical stirrer. The content was heated up to $130{ }^{\circ} \mathrm{C}$ and then styrene in different per hundred of resin (phr) along with bezoyl peroxide ( $0.1 \mathrm{wt} \%$ of styrene) added slowly in the same reaction mixture. The reaction mixture was heated for two hrs to obtained SMAPEA as end product. On completion of reaction the product was cooled at room temperature. The excess of solvent removed in a rotary vacuum evaporator at reduce pressure.

\section{Characterization}

Physicochemical characterizations like specific gravity, refractive index, iodine value, hydroxyl value, saponification value of the samples were performed as per standard laboratory methods ${ }^{1,2,5}$. The structural elucidation of the polymer samples were carried out by FT-IR spectrometer (Perkin-Elmer Cetus instruments, Norwalk CT, USA) using $\mathrm{NaCl}$ cell. ${ }^{1} \mathrm{H}$ NMR and ${ }^{13} \mathrm{C}$ NMR spectra were recorded on JEOL GSX $300 \mathrm{MHz}$ FX-1000 spectrometer using deuterated chloroform as a solvent and tetramethyl silane (TMS) as an internal standard.

\section{Preparation of coatings}

Coatings of SMAPEA resins were prepared on mild steel strips, $70 \times 25 \times 1 \mathrm{~mm}$ size for pysicomechanical test. The mild steel strips were polished on various grade of silicon carbide papers, then washed with distilled water, degreased with alcohol and carbon tetrachloride. They were dried under vacuum for several hours. The coatings were developed on these specimens by brush technique using solution of $60 \mathrm{wt} \%$ of resins. Coated strips were baked at $140{ }^{\circ} \mathrm{C}$ for 20 minutes. Elcometer (Model 345; Elcometer instrument, Manchester, UK) was used to measure the coating thickness. The thicknesses of these coatings were found between $75 \pm$ $5 \mu \mathrm{m}$. The coated samples were evaluated for the scratch hardness (BS 3900), bending test on conical mandrel, and impact resistance (IS: 101 part 5/Sec.31988) tests.

\section{Results and Discussion}

Figure $1(\mathrm{a} \& \mathrm{~b})$ illustrate the reaction scheme for the synthesis of MAPEA and SMAPEA. The MAPEA was prepared by aminolysis of triglyceride oil with diethanol amine followed by 
the poly(condensation) of HEMAFA with phthalic acid. MAPEA resin was further treated with styrene in different phr (Table 2) to obtain a series of SMAPEA resins. Styrene grafted at allylic position of non-conjugated fatty acid chain, free radicals serve to modify the growth of styrene chain by chain transfer mechanism. Physicochemical characterization results show that decrease in hydroxyl value as well as acid value from HEMAFA to MAPEA. This is due to formation of repeating ester linkages in expense these functional groups. The progressive increase in viscosity and specific gravity indicates that increase in molecular weight of the resin.
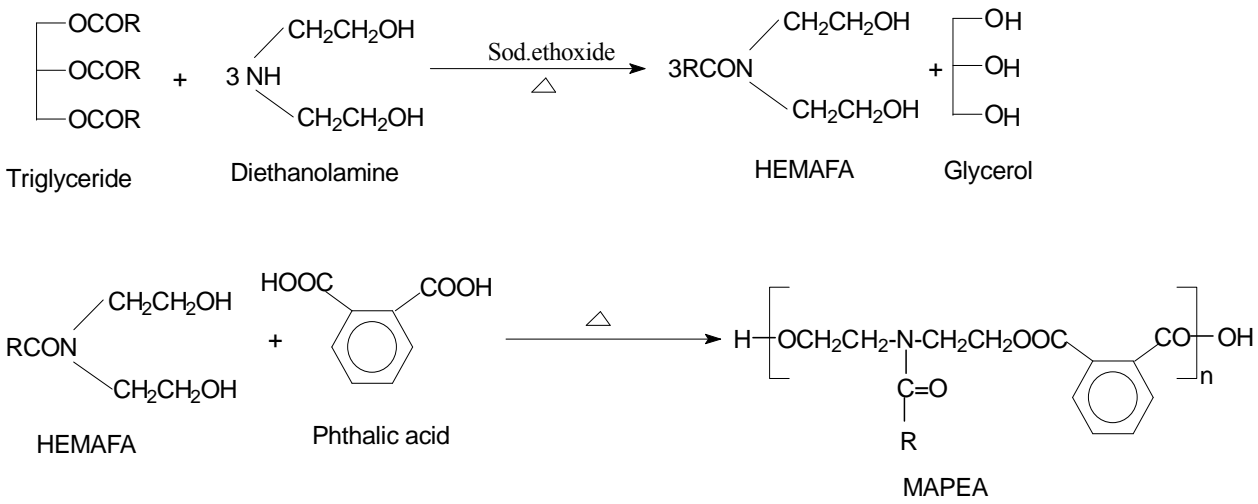

$\mathrm{R}=$ Long alkyl chain fatty acid of oil

Figure 1(a). Reaction scheme for formation of MAPEA
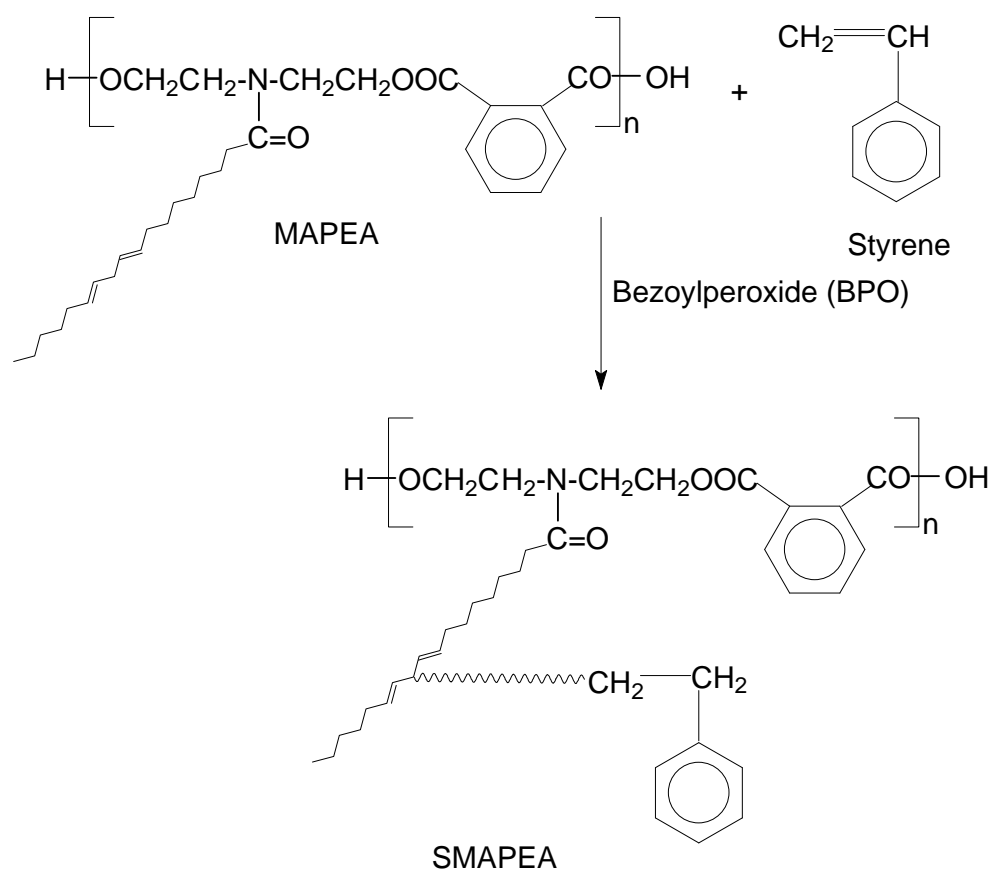

Figure 1(b). Reaction scheme for formation of SMAPEA 
Table 2. Physicochemical properties of MAPEA and SMAPEA ${ }^{\mathrm{a}}$

\begin{tabular}{|c|c|c|c|c|c|c|}
\hline S.No. & Properties & MAPEA & SMAPEA-5 & MAPEA- & MAPEA- & MAPEA-20 \\
\hline 1. & $\begin{array}{l}\text { Gardener } \\
\text { Color }\end{array}$ & 8 & 8 & 7 & 7 & 7 \\
\hline 2. & Specific gravity & 0.956 & 0.960 & 0.964 & 0.968 & 0.978 \\
\hline 3. & $\begin{array}{c}\text { Inherent } \\
\text { viscosity }(\mathrm{dL} / \mathrm{g})\end{array}$ & 0.612 & 0.616 & 0.624 & 0.634 & 0.648 \\
\hline 4. & $\begin{array}{l}\text { Refractive } \\
\text { index }\end{array}$ & 1.5062 & 1.5074 & 1.5082 & 1.5090 & 1.5122 \\
\hline 5. & Iodine value & 36.8 & 34.47 & 32.7 & 31.48 & 30.18 \\
\hline 6. & $\begin{array}{l}\text { Acid value } \\
\text { (mg KOH) }\end{array}$ & 7.42 & 6.66 & 6.36 & 6.08 & 5.82 \\
\hline 7. & $\begin{array}{c}\text { Saponification } \\
\text { value }\end{array}$ & 148.0 & 141.2 & 134.5 & 128.28 & 124.2 \\
\hline
\end{tabular}

Table 2 indicates the effect of loading of styrene in the polymer. The values of physicochemical characteristics like acid value, saponification value, hydroxyl value and iodine value decreases gradually on increasing the phr of styrene but remain constant for the same amount of MAPEA in the reaction. These observation especially iodine value indicates that grafting occur at allylic position without affecting the unsaturation of fatty acid.

IR spectrum of HEMAFA shows the strong band at $3420 \mathrm{~cm}^{-1}$ (broad band for primary alcoholic group). Band for non-conjugated unsaturation of fatty acid appear at $3010 \mathrm{~cm}^{-1}$ with an additional weak shoulder around $2960 \mathrm{~cm}^{-1}$ for terminal methyl group. The bands for the chain $\mathrm{CH}_{2}$ asymmetric and symmetric stretching appears at 2925 and $2842 \mathrm{~cm}^{-1}$. The band for the carbonyl of amide appears at $1640 \mathrm{~cm}^{-1}$ confirms the aminolysys of triglyceride where as the band for $\mathrm{C}-\mathrm{N}$ stretching appears at $1372 \mathrm{~cm}^{-1}$. The ${ }^{1} \mathrm{H}$ NMR spectrum of HEMAFA shows the multiplet peak for the proton of double bonded carbon at $\delta=5.26-5.32$ ppm, $\mathrm{CH}_{2}$ attached to hydroxyl group appears at $\delta=4.42 \mathrm{ppm}$, where as peak at $\delta=3.60 \mathrm{ppm}$ for the $\mathrm{CH}_{2}$ attached to nitrogen of amide. The $\mathrm{CH}_{2}$ attached to $-\mathrm{C}=\mathrm{O}$ of amide appear at $\delta$ $=1.62 \mathrm{ppm}$, aliphatic chain $\mathrm{CH}_{2}$ appears at $\delta=1.22-1.42 \mathrm{ppm}$ and terminal methyl group appears at $\delta=0.88 \mathrm{ppm}$. The ${ }^{13} \mathrm{C}$ NMR spectrum of HEMAFA shows the characteristic peak at $\delta=160.2 \mathrm{ppm}$ for carbon of carbonyl while double bonded carbons of fatty amide appear at $\delta=121.4-122.8 \mathrm{ppm}$. Characteristic peaks for allylic methylene carbon appears at 34.2$36.4 \mathrm{ppm}$, different $\mathrm{CH}_{2}$ of fatty amide chain appear between $\delta=22.2-29.4 \mathrm{ppm}$ and terminal $\mathrm{CH}_{3}$ appear at $\delta=13.4 \mathrm{ppm}$.

The IR spectrum of MAPEA shows the broad band at $3416 \mathrm{~cm}^{-1}$ for the terminal $-\mathrm{OH}$ groups, bands for asymmetric and symmetric $\mathrm{CH}_{2}$ group at $2930 \mathrm{~cm}^{-1}$ and $2854 \mathrm{~cm}^{-1}$. The band at $1750 \mathrm{~cm}^{-1}$ for the carbonyl of ester in addition to band at $1644 \mathrm{~cm}^{-1}$ of the amide, confirms the formation of ester linkage; whereas the characteristic bands of benzene ring appear at1610, 1590, $750 \mathrm{~cm}^{-1}$.

The ${ }^{1} \mathrm{H}$ NMR spectrum of MAPEA show the aromatic protons at $\delta=7.36-7.56 \mathrm{ppm}$, peaks for the proton of double bonded carbon at $\delta=5.29-5.36 \mathrm{ppm}$ while allylic protons between double bonds appears at $\delta=2.42 \mathrm{ppm}$, sharp peak of $\mathrm{CH}_{2}$ adjacent to carbonyl of ester at $\delta=2.04 \mathrm{ppm}$, broad peak for chain $\mathrm{CH}_{2}$ appears at $\delta=1.24-1.46 \mathrm{ppm}$ and terminal $\mathrm{CH}_{3}$ appear at $\delta=0.90 \mathrm{ppm} .{ }^{13} \mathrm{C}$ NMR spectrum of MAPEA show peak for carbonyl of ester at $\delta=172.6 \mathrm{ppm}$ in addition to carbonyl of amide at $\delta=162.6 \mathrm{ppm}$. 
The aromatic ring carbons appear at $\delta=132.2-128.4 \mathrm{ppm}$ while double bonded carbons of fatty amide appear at $\delta=128.2-126.4 \mathrm{ppm}$. Allylic $\mathrm{CH}_{2}$ appear at $\delta 42.6$ ppm, fatty amide chain $\mathrm{CH}_{2}$ appear at $\delta=29.6-22.6 \mathrm{ppm}$ and terminal methyl carbon appear at $\delta=14.2 \mathrm{ppm}$.

IR spectrum of SMAPEA shows the broad band for $-\mathrm{OH}$ groups at $3446 \mathrm{~cm}^{-1}$. Aromatic $\mathrm{C}-\mathrm{H}$ appears at $3050 \mathrm{~cm}^{-1}$ while bands for $\mathrm{CH}_{2}$ asymmetric and symmetric appear at $2964 \mathrm{~cm}^{-1}$ and $2862 \mathrm{~cm}^{-1}$. The bands for carbonyl of repeating ester linkage and amide are appear at $1766 \mathrm{~cm}^{-1}$ and $1650 \mathrm{~cm}^{-1}$ respectively. The band at $1660,1596,770,721 \mathrm{~cm}^{-1}$ for benzene rings of phthalic acid and styrene. ${ }^{1}$ HNMR spectrum of SMAPEA show the peaks at $\delta=6.92-7.84 \mathrm{ppm}$ due to aromatic proton of phthalic acid and styrene while peaks for the proton of double bonded carbon at $\delta=5.34-5.46 \mathrm{ppm}$. $\mathrm{CH}_{2}$ attached to nitrogen of amide appear at $\delta 3.84-4.12 \mathrm{ppm}$ where as allylic methylene and methine protons appear at 2.56 and $2.86 \mathrm{ppm}$ respectively. Sharp peak for $\mathrm{CH}_{2}$ adjacent to ester appears at $\delta=2.32 \mathrm{ppm}$, fatty amide chain $\mathrm{CH}_{2}$ appear as multiplet at $\delta 1.36-1.48 \mathrm{ppm}$ while proton of terminal methyl group at $\delta=0.93 \mathrm{ppm} .{ }^{13} \mathrm{C}$ NMR spectrum show the peaks at $\delta=176.8 \mathrm{ppm}$ and $\delta 164.6 \mathrm{ppm}$ for the carbonyl of ester and amide. Closely spaced peaks at $\delta 144.6,133.5,132.0,131.8$, $127.4,126.4,125.8 \mathrm{ppm}$ due to carbon of aromatic rings ${ }^{22}$ (phthalic acid and styrene). Double bonded carbons appear at128.6-130.4 ppm where as carbons of allylic methine and methylene appear at $\delta 56.4$ and $\delta 46.6 \mathrm{ppm}$ respectively. Peaks for chain $\mathrm{CH}_{2}$ of fatty amide appears at $\delta$ 29.6-22.4 ppm while carbon of terminal methyl group appears at $15.2 \mathrm{ppm}$.

\section{Coating properties}

The films of SMAPEA containing different phr of styrene (Table 3) developed on the mild steel coupons to investigate the film characteristic like flexibility, resistance to scratch, impact resistance, and gloss. All the samples show the good impact resistance more than $100 \mathrm{Lb} / \mathrm{in}$, which indicates the good adhesion of the polymeric films to the metal surface. On increasing the styrene content this property notably improved up to the $15 \mathrm{phr}$ of styrene after which no significant improvement was noticed. The scratch hardness results reveal that on increasing the styrene content in the polymer rigidity of the film increases. This is presumably due to increase in cross-linked density. However, flexibility of the polymeric film deteriorated on increasing the content of styrene in the polymer. The polymeric films up to the loading of $15 \mathrm{phr}$ of styrene pass the bending test on $1 / 8$ " conical mandrel. Small cracks were observed in case of SMAPEA-20, presumably due to the presence of closely spaced benzene rings of styrene ${ }^{10,16,23}$.

Table 3. Physico-mechanical properties of SMAPEA

\begin{tabular}{cccccc}
\hline $\begin{array}{c}\text { S. } \\
\text { No. }\end{array}$ & Resin code $^{\mathrm{a}}$ & $\begin{array}{c}\text { Bending test } \\
1 / 8 \text { in }\end{array}$ & $\begin{array}{c}\text { Impact resistance } \\
\text { Lb/in }\end{array}$ & $\begin{array}{c}\text { Scratch } \\
\text { hardness, kg }\end{array}$ & $\begin{array}{c}\text { Gloss at } \\
45^{\circ}\end{array}$ \\
\hline 1. & SMAPEA-5 & Pass & 100 & 2.00 & 60 \\
2. & SMAPEA-10 & Pass & 120 & 2.10 & 64 \\
3. & SMAPEA-15 & Pass & 130 & 2.40 & 66 \\
4. & SMAPEA-20 & Fail & 130 & 2.45 & 66 \\
\hline
\end{tabular}

${ }^{a}$ Last digit indicates the loading of styrene in phr

\section{Conclusion}

From this study it can be concluded that the non-edible, non-traditional and annually renewable Malea azedarach seed oil can be utilized successfully for the synthesis of styrenated poly (ester-amide) resin. The synthesized resins were characterized by taking 
physicochemical analysis and spectroscopic studies. It has also been observed that SMAPEA-15 shows the optimum physic-mechanical properties. The synthesis of SMAPEA therefore gives a profitable utilization of MASO rot away at the various plantations in each season.

\section{Acknowledgement}

The authors would like to thank the authorities of G. F. College, Shahjahanpur, UP, India for providing necessary facilities for carrying out this study and Mr. A. Wahab for valuable suggestions.

\section{References}

1. Ahmad S, Ashraf S M, Hasnat A, Yadav S and Jamal A, J Appl Polym Sci., 2001, 82(8), 1855-1865; DOI:10.1002/app.2029

2. Ansrai S H, Naseem M, Hasnat A and Ahmad S A, Biosci Biotech Res Asia., 2011, 8(2), 829-832; DOI:10.13005/bbra/944

3. Ansari S H, Hasnat A and Ahmad S A, Orient J Chem., 2012, 28(2), 1015-1018.

4. Zafar F, Ashraf S M and Ahmad S, Reactive Functional Polym., 2007, 67(10), 928935; DOI:10.1016/j.reactfunctpolym.2007.05.018

5. Ahmad S, Ashraf S M, Naqvi F, Yadav S and Hasnat A, Prog Org Coat., 2003, 47(2), 95-102; DOI:10.1016/S0300-9440(03)00015-8

6. Ahmad S, Ashraf S M A, Naqvi F, Yadav S and Zafar F, J Macromolecular Sci. Part A: Pure and Appl Chem., 2006, 43(9), 1409-1419; DOI:10.1080/10601320600820280

7. Ahamad S, Imran G, Ahmad S A and Hasnat A, Chem Sci Trans., 2015, 4(3), 858864; DOI:10.7598/cst2015.1060

8. Zafar F, Sharmin E, Ashraf S M and Ahmad S, J Appl Polym Sci., 2004, 92(4), 25382544; DOI:10.1002/app.20218

9. Akintayo C O and Adebowale K O, Prog Org Coat., 2007, 50(4), 207-212; DOI:10.1016/j.porgcoat.2003.09.017

10. Ahmad S, Ashraf S M, Kumar S, Alam M and Hasnat A, Indian J Chem Technol., 2005, 12 193-197.

11. Samarth N B and Mahanwar P A, Open J Org Polymer Mater., 2015, 5, 1-22.

12. Gunduz G, Khalid A H, Mecidoglu I A and Aras L, Prog Org Coat., 2004, 49(3), 259-269; DOI:10.1016/j.porgcoat.2003.09.021

13. Toliwal S D and Patel K, J Sci Ind Res., 2006, 65, 590-593.

14. Yadav S, Zafar F, Hasnat A and Ahmad S, Prog Org Coat. 2009, 64(1), 27-32; DOI:10.1016/j.porgcoat.2008.07.006

15. Lebarbe T, Maisonneuve L, Nguyen T H N, Gadenne B, Alfos C and Cramail H, Polym Chem., 2012, 3, 2842-2851; DOI:10.1039/C2PY20394D

16. Ahmad S, Ashraf S M, Hasnat A and Noor A, Indian J Chem Technol., 2001, 8, 176-180.

17. Ansari, S H, Imran, G, Naseem M, Ahmad S A and Hasnat A, Orient J Chem., 2012, 28, 607-612.

18. Guner F S, Yagci Y and Erciyes A T, Prog Polym Sci., 2006, 31(7), 633-670;

19. Mahapatra S S and Karak N, Prog Org Coat., 2004, 51(2), 103-108; DOI:10.1016/j.porgcoat.2004.07.003

20. Ahmad S, Ashraf S M, Naqvi F, Yadav S and Hasnat A, J Polym Mater., 2001, 18, 53-60.

21. Ambastha S P, Useful Plants of India, CSIR New Delhi 1986.

22. Silverstein R M, Bassler G C and Morril T C, Spectroscopic identification of organic compounds, $5^{\text {th }}$ Edn., (John Wile y \& Sons, New York) 1991.

23. Sounders K J, Organic Polymer Chemistry, $2^{\text {nd }}$ Edn., (Chapman and Hall, USA) 1988. 